Prof. J. B. S. Haldane for a scheme of calculation, which we intend to use as soon as we have sufficient data.

E. Sillegtroni

I. Branco

G. Montalenti

Medical Clinic,

M. Siniscalco

University of Rome, and

Institute of Genetics,

University of Naples.

Nov. 23.

${ }^{2}$ Silvestroni, E., and Bianco, I., Boll. Atti R. Accad. Med. Roma, 69, 293 (1943-44); Policlinico, Sez. Med., 52, 105 and 137 (1945); Policlinico, Sez. Prat., 54, 1359 (1947)., Min. Med., 2, $206(1946)$. Valentine, W. N., and Neel, J. V., Arch. Int. Med., 74, 185 (194)

Neel, J. v., and Valentine, W. W. .', Genetics, 32,38 (1947).

${ }^{3}$ Silvestroni, E., and Blanco, I., Policlinico, Sez. Med., 52,105 and clinico Sez. Prat 55, 417 (1948), Min Med. 1205 '(1948) Ric. Scient. Ricostr., 19, 230 (1949); Policlinico, Sez. Prat., 5B, 602 and 906 (1949).

'Haldane, J. B. S., Proc. Roy. Soc., B, 135, 147 (1948).

\section{Arterenol Content of the Mammalian and Human Adrenal Medulla}

Holtz, Credner and Kroneberg ${ }^{1}$ some years ago showed that in human urine there is a sympathetic pressor substance called by them 'urosympathin'. In patients with essential hypertension, 'urosympathin' was secreted in larger quantities than in normal individuals. The activesubstance isolated by absorption on aluminium hydroxide and elution with sodium dihydrogen phosphate was evaluated against adrenaline using the blood pressure of the cat for assay. A dose of 'urosympathin' equal in this assay to a certain amount of adrenaline had a weaker effect on the blood pressure of the rabbit and on the isolated rabbit intestine. Contrary to adrenaline, its pressor effect was not reversed by sympathicolytics but only weakened. Polyphenoloxidase destroyed its activity. Where the 'urosympathin' differed pharmacologically from adrenaline, it resembled the demethylated derivative nor-adrenaline or arterenol. Experiments ${ }^{2}$ not yet published showed that the 'urosympathin' of animals' urine also contains arterenol as chief constituent.

Two sources of urinary arterenol were considered ${ }^{1}$ : (1) the sympathetic nerves, in view of the pharmaco. logical similarity between arterenol and the "sympathin E' of Cannon; (2) the suprarenal medulla.

The work of Eulers has shown that the sympathetic activity of extracts from sympathetic nerves and ganglia is mainly due to $\mathrm{x}$-arterenol. In blood pressure experiments, after giving yohimbine we found ${ }^{1}$ that the action of suprarenal extracts - in contrast to the action of pure adrenaline-could be imitated by adrenaline-arterenol mixtures of a certain composition. Subsequent investigations indicated that extracts and hormone crystallizates from ox and pig suprarenals contained about 30 per cent arterenol in addition to adrenaline. To differentiate between the two sympathomimetics, use was made of the fact that L-arterenol has a hyperglycæmic activity ten times weaker than L-adrenalines. Amino-nitrogen determinations performed on the crystallizates were in agreement with the results of the biological assay. The final proof of the occurrence of nor-adrenaline in the suprarenals was produced also by Tullar", who isolated chemically the substance from U.S.P. epinephrine, and also by Bergström, Euler and Hamber's, who isolated it from the adrenals of cattle.
These investigations have now been extended to include the suprarenals of other mammals, including man. For differentiation between arterenol and adrenaline the following differential criteria were used: (1) After giving cocaine, the blood pressure effect of arterenol is more strongly potentiated than that of adrenaline. Arterenol then may be three to five times more active than adrenaline. (2) On the isolated rabbit ileum, adrenaline has twice the inhibitory action of arterenol. (3) After storage on ice for three to five days, the rabbit intestine responds only poorly to adrenaline. Contrary to the effect with fresh intestine, arterenol now is the more active substance.

Using the above methods, the adrenal medulla of dog, cat and man, in addition to the suprarenals of ox and pig, were proved to contain considerable amounts (sometimes more than 30 per cent) of arterenol along with adrenaline. On the other hand, in rabbit suprarenals no arterenol, only adrenaline, was detected.

The latter result is of particular interest in that experimental investigations of other authors favour the assumption that, in a higher degree in rabbits than in other species, adrenaline may participate as chemical mediator in the transmission of autonomic nervous impulses. Thus, for example, according to Gaddum and Kwiatowski ${ }^{\circ}$, the chemical transmitter liberated by electrical stimulation of the sympathetic nerves of the perfused rabbit ear seems to be adrenaline. Further, Kroneberg'10, using Shaw's ${ }^{11}$ method for the colorimetric determination of adrenaline, proved that rabbit heart extracts, like adrenaline, showed an intensification of colour after treatment with alkali, whereas human heart extracts and extracts from cats, dogs, oxen and pigs, like arterenol in these circumstances, did not give a change of colour intensity.

Nevertheless, the main source of 'urosympathin', that is, the arterenol of urine, probably will be the sympathetic - 'arterenergic'12 nerves, and the augmentation of 'urosympathin' in essential hypertension, as pointed out several years ago, will be caused by an increased discharge of arterenol from the arterenergic nerve-endings into the vessel walls. The arterenol content of the urine thus becomes an indicator of the reactivity and the 'tonus' of the sympathetic nervous system.

\section{P. Holtz \\ H. J. SCHÜMANN}

Pharmacological Institute, University, Rostock. Oct. 11

1 Holtz, P., Credner, K., and Kroneberg, G., Arch. exp. Path. u. Pharmakol., 204,'228'(1944-47).

${ }^{2}$ Holtz, P., Kroneberg, G., and Schümann, H. J., Arch. exp. Path. u. Pharmakol. (in the press).

${ }^{3}$ Euler, U. V., Acta physiol. Scand., 11, 168 (1946) ; 12, 73 (1946); $16,63(1948)$.

${ }^{4}$ Holtz, P., Verhandl. deutsch. Physiol. Ges., Frankfurt (1948). Schümann, H. J., Klin. Wschr., 605 (1948); Arch. exp. Path. u. Pharmakol., 206, 475 (1949). Holtz, P., and Schümann, H. J., $484(1949)$

${ }^{5}$ Schümann, H. J., Arch. exp. Path. $u$. Pharmakol., 206, 164, 475 (1949).

${ }^{6}$ Holtz, P., Schümann, H. J., Langenbeck, W., and LeBlanc, H., Naturw., 191 (1948)

'Tullar, B. F., Science, 109, 536 (1939).

\& Bergström, S., v. Euler, U. S., and Hamberg, U., Act, chem. Scand., 3,305 (1949).

- Gaddum, J. K., and Kwiatowskd, H., J. Physiol., 96, 385 (1939).

10 Kroneberg, G. (unpublished results).

11 Shaw, F. H., Biochem. J., 32, 19 (1938).

${ }^{12}$ Holtz, P., Klin. Wschr., 64 (1949). 